\title{
Redes de relações pessoais e prática empresarial: um estudo sobre as empresas de comunicação e a política no Rio Grande do Sul
}

\author{
Fernanda Rios Petrarca \\ Doutora em Sociologia (Universidade Federal do Rio Grande do Sul) \\ Professora associada da Universidade Federal de Sergipe \\ Aracaju, Brasil \\ f.petrarca@hotmail.com
}

Este artigo analisa o papel das redes de relações entre empresários da comunicação e a política no Rio Grande do Sul. A partir do estudo de caso de duas empresas de comunicação do estado, identificamos um conjunto de mudanças sociais e políticas que conduziram a uma diversificação nas formas de relação entre o empresariado e a política. Por um lado, o período de ascensão da empresa Caldas Júnior representa um momento em que a base das relações entre o empresariado ocorria por meio dos vínculos diretos com o Estado. Por outro, o momento de ascensão da empresa Rede Brasil Sul (RBS) ocorre em um contexto em que as relações com a esfera política haviam se diversificado e com isso era preciso ampliar as redes de relações. Com base nisso, foi possível identificar as transformações nos mecanismos de acesso à política e as redes de relações que fundamentam as práticas dos empresários.

Palavras-chave: empresários, política, relações pessoais, clientelismo, Caldas Junior, RBS.

\section{Introdução}

Este artigo tem como problema central a análise das redes de relações pessoais que os empresários mobilizam para ter acesso à política como parte dos mecanismos que fundamentam suas práticas. Esta problemática se situa entre as correntes que visam analisar o peso dos vínculos pessoais na construção de um espaço político e econômico (Auyero, 2002; Bezerra, 1995; Combes, 2011; Briquet; 
Sawicki, 1998) e parte da noção de rede como um conjunto de laços sociais (formais ou informais) mobilizados, sejam eles interpessoais ou categoriais, para fins específicos (Barnes, 1987).

Provenientes dos estudos sobre sociedades mediterrâneas, as redes pessoais - como um tipo específico de redes - e as chamadas "práticas clientelistas" representaram, nas ciências sociais de modo geral, um fenômeno típico das sociedades tradicionais submetidas ao intercâmbio de favores entre pessoas ou entre patrão-cliente para ter acesso aos recursos estatais.Visto pela literatura especializada como uma prática de democracias não consolidadas e, portanto, destinado a desaparecer (Kitschelt; Wilkinson, 2007), o uso do vínculo pessoal para a obtenção de benefícios ficou circunscrito ao estudo de comunidades rurais, expandindo-se, posteriormente, para as sociedades latino-americanas. Atualmente, um conjunto de autores se esforça para demonstrar que práticas clientelistas, ou baseadas em redes de trocas pessoais (amizade, parentesco, alianças), coexistem em sistemas democráticos consolidados, contribuindo para a dinâmica de funcionamento de diferentes esferas sociais (Briquet; Sawicki, 1998; Ayuero, 2011; Combes, 2011; Bezerra, 1995; 2017).

Diante dessas discussões, o objetivo do artigo é demonstrar, a partir de um estudo de caso e de um conjunto de relatos biográficos, o sistema de trocas, baseado nas redes pessoais, como a lógica que fundamenta o intercâmbio entre o Estado e as empresas. $\mathrm{O}$ universo empírico que serviu de base consistiu no levantamento de dados históricos ${ }^{1}$ das duas maiores empresas do setor de comunicação do estado do Rio Grande do Sul, a saber: Caldas Júnior e Rede Brasil Sul (RBS). O exame dos laços pessoais mobilizados permite compreender os mecanismos de acesso à política.

A literatura que trata das relações entre o setor econômico e o Estado tem destacado, dentre outras questões: o papel da ação coletiva do empresariado (Bianchi, 2007) e as condições de possibilidade da representação empresarial (Offerlé, 2009); a lógica da ação estatal e sua ingerência cada vez mais forte na economia como um estímulo para a intervenção empresarial em outras esferas (Haggard; Maxfield; Schneider, 1997); o peso dos contextos históricos particulares para a forma de ação coletiva dos empresários.

A bibliografia brasileira que se ocupa desse objeto enfrenta a difícil tarefa de definir a força do empresário brasileiro como ator no jogo político (Mancuso, 2007). Uma das questões que tem sido levantada nessa direção diz respeito à trajetória dos empresários brasileiros, marcada por uma intensa capacidade de participação, apoiando-se em governos e adaptando-se à instabilidade na defesa dos seus interesses (Gros, 2003; Bresser-Pereira; Diniz, 2009; Diniz, 2010). A agenda atual de problemas ainda contempla estudos sobre o processo de recrutamento, o comportamento e a cultura dos empresários (Costa; Roks; Santos Filho, 2012; Costa, 2014).

Entretanto, apesar da vasta bibliografia sobre o empresariado, a agenda de pesquisa ainda deixa em aberto o exame das práticas empresariais e suas múltiplas maneiras de

1 Os dados foram coletados em materiais diversificados, tais como: livros produzidos sobre a história da empresa; entrevistas dos proprietários concedidas a veículos de imprensa e a biógrafos; material de jornal e revistas; biografias de jornalistas e políticos, dentre outros. 
se relacionar e negociar com a política governamental. Levando em consideração essas questões, nosso problema central é a análise das redes como parte das estratégias de ação política dos empresários, as quais variam desde contatos diretos com tomadores de decisão, por meio da participação em espaços formais (comissões) ou informais (jantares, almoços, festas), até a presença oficial em organismos estatais (conselhos, comissões, grupos de trabalho), formação de coalizões e contratação temporária de indivíduos em defesa de interesses (Mancuso, 2007). Nessas condições, a rede representa um conjunto de laços ativados como meio de acesso não só a recursos públicos como também a benefícios, e o político se torna o mediador entre os empresários e o atendimento das suas demandas. Essa relação, contudo, é regulada por obrigações, retribuições e comprometimentos que variam de acordo com o contexto histórico (Barnes, 1987; Bezerra, 1995; Kuschinir, 2007).

Para dar conta da problemática proposta, o artigo está dividido em três momentos centrais. Num primeiro momento, é preciso destacar a estreita relação histórica entre as empresas de comunicação e a política, a qual contribuiu para a estruturação deste setor. Num segundo momento, abordaremos a empresa Caldas Junior e o peso das relações centradas no líder (Landé, 1977). E, por fim, num terceiro momento, a partir do estudo da empresa RBS, demonstraremos o peso das redes de relações pessoais diversificadas como forma de acesso à política, tendo como referência a patronagem, a amizade e a aliança pessoal. $\mathrm{O}$ exame dos dois casos permite identificar modalidades distintas de relação com a política e de uso das relações pessoais.

\section{As empresas de comunicação e a política: um estudo de caso}

A estreita relação entre o jornalismo e a política já foi objeto de um conjunto diversificado de pesquisas (Alonso, 2002; Miceli, 2001;Vidal; Souza, 2003; Petrarca, 2010; 2013) que, dentre outras coisas, enfatizaram a presença significativa, na imprensa, de políticos, homens de letra, advogados, ora como jornalistas, ora como proprietários de jornais. Além disso, a dinâmica de funcionamento e as formas de contratações realizadas pelos jornais revelaram as interferências que o jornalismo sofria da política governamental, mesmo em um período em que à atividade se atribuía uma condição de independência em relação à atividade política. $\mathrm{O}$ processo de formação, configuração e estruturação dos grupos de comunicação como empresas teve apoio fundamental do Estado - principalmente após a Primeira República -, o qual favoreceu o desenvolvimento de um mercado jornalístico e tornou-se o principal promotor da constituição de uma "grande imprensa". Investimentos estatais, como publicidade e concessão de subsídios especiais, além do fechamento de jornais partidários, foram algumas das medidas que contribuíram para o encerramento de pequenos jornais e para o crescimento de grandes empresas com estruturas específicas, permitindo que um mesmo empreendimento controlasse vários veículos ao mesmo tempo (rádio, televisão, jornais, revistas, editoras, filmes). 
O aparecimento da televisão, como uma concessão pública, nos anos 1950, intensificou as relações entre Estado e empresas de comunicação, uma vez que os canais abertos passaram a ser de propriedade do Estado, com poder de conceder a algumas empresas, por meio de licitações públicas, a permissão para a transmissão. Desse modo, a emergência dos conglomerados de comunicação como empreendimento - independente de partidos, facções, grupos sociais e religiosos - aparece apoiada na política governamental. Mas o período de maior investimento estatal no setor empresarial desponta no final da década de 1960, tendo como início o Golpe Militar de 1964. A consolidação das bases empresariais ganha impulso nesse período em que o governo oferece a possibilidade de as empresas contribuírem na definição da agenda política e econômica nacional.

Os investimentos estatais e o aumento da publicidade tiveram uma contribuição decisiva para que as empresas de comunicação se transformassem em "grandes empresas". Assim, a relação entre o setor das comunicações e o Estado, no Brasil, é marcada, por um lado, por momentos de censura à imprensa, por meio dos processos de fechamento político, como a ditadura de Vargas - dentre 1937 e 1945 - e a ditadura militar de 1964 até 1985. Por outro lado, é caracterizada por intensos investimentos estatais em empresas privadas de comunicação, com subsídios e concessões especiais. Os períodos ditatoriais são caracterizados como momentos de estabelecimento e crescimento de grandes conglomerados ${ }^{2}$ de mídias e empresas de comunicação. Com o fechamento de muitos periódicos vinculados a grupos partidários, as empresas passaram a liderar o setor com o apoio do Estado. Já os períodos democráticos são, em geral, caracterizados como períodos de baixa regulação, em que algumas empresas puderam garantir o controle de vários veículos e manter sociedade com grupos internacionais e políticos profissionais. Como exemplo de empresas que cresceram em períodos ditatoriais, temos os Diários Associados, nos anos 1940, e a Rede Globo de Televisão, nos anos 1970.

Atualmente, um dado produzido pela organização Fórum Nacional pela Democratização da Comunicação (FNDC), através do projeto “Os Donos da Mídia”, revela que, no Brasil, 271 políticos profissionais são sócios ou diretores de, aproximadamente, 324 veículos de comunicação. O destaque é dado para prefeitos, que lideram a estatística com $54,24 \%$, seguidos de deputados estaduais $(20,3 \%)$, deputados federais $(17,7 \%)$ e senadores (7,38\%). Esse dado, produzido pela organização, revela ainda os partidos que prevalecem, além dos estados e dos meios de comunicação que mais contam com políticos como membros do quadro societário. Dentre os partidos, podemos perceber DEM, com 21,4\%; PMDB, com 17,71\%, e PSDB, com 15,87\%. Já os estados são: Minas Gerais (38), São Paulo (28) e Bahia (24). Por fim, os meios de comunicação são as rádios de onda média e as FMs, com cerca de 80\%, seguidos das rádios comunitárias, com 9,57\%, e as televisões, com 8,95\%. É importante frisar que essa estatística não considera famílias de políticos que controlam alguns veículos em determinados estados. Este é o caso especialmente da

2 Conglomerados de mídia é a forma como se denomina uma empresa que controla uma diversidade de veículos de comunicação ao mesmo tempo, tais como: rádio, revista, jornais, editoras, filmes. 
família Sarney, que controla os principais espaços de comunicação no estado do Maranhão; da família Magalhães, na Bahia; de Inocêncio Oliveira, em Pernambuco; de Alves e Agripino Maia, no Rio Grande do Norte; de Albano Franco, em Sergipe, e de Collor de Mello, no estado de Alagoas ${ }^{3}$.

O estado do Rio Grande do Sul apresenta onze políticos que são sócios de empresas de comunicação no total, as quais são predominantemente, como visto em outras situações regionais, as rádios de onda média $(84,62 \%)$ e as FMs $(15,38 \%)$. Os prefeitos dominam o topo da lista, com $72,73 \%$, seguidos dos deputados estaduais $(18,18 \%)$ e federais $(9,09 \%)$. Já com relação aos partidos, são cinco ao total: PDT (36,36\%), PP (27,27\%), PMDB (18,18\%); PPS (9,09\%) e DEM (9,09\%). Além disso, não figura no estado a presença de famílias de políticos como proprietárias de grupos de comunicação que envolvem mais de um veículo, como observado em outros estados do país.

Contudo, apesar de no estado do Rio Grande do Sul as duas empresas analisadas não constituírem propriedade de políticos nem de suas famílias, elas se tornam casos extremamente relevantes de estudo da relação com o Estado, uma vez que tal relação não pode ser compreendida apenas no seu contato direto com essa esfera. Por se tratar de empreendimentos independentes de partidos, suas táticas, técnicas e estratégias para acesso ao Estado se complexificam.

Além disso, por tratar-se de empreendimentos jornalísticos que vivenciaram um crescimento importante no setor da comunicação em momentos tão contrastantes, eles representam também mudanças específicas nas redes de relações do empresariado com a esfera da política, sobretudo com o Estado. De um lado, a empresa Caldas Junior se destaca - durante as décadas de 1960 e 1970 - como empreendimento no ramo das comunicações, num contexto em que a base das relações com o Estado estava fundamentada nos contatos pessoais entre os empresários e representantes da esfera estatal, como burocratas responsáveis por setores específicos que facilitavam e intermediavam a relação com o Estado. Tal característica exigia do empresariado uma habilidade para lidar com as redes pessoais e uma capacidade de estabelecer laços duráveis e relações de confiança.

De outro lado, a RBS ganha projeção - nos anos 1980 e 1990 - num momento em que as relações se diversificam e o empresariado precisou multiplicar seus investimentos na esfera da política. Isso incluía desde a participação direta, por meio das carreiras eletivas (deputados, senadores), até o investimento em espaços de representação empresarial como canais de negociação com o Estado. Assim, a abertura da arena política com o processo de redemocratização, a ampliação das formas de participação e o aparecimento de novos atores, como as entidades de trabalhadores, sindicatos, movimentos, proporcionaram novas formas de representação de interesses aos empresários. Tal situação promoveu a progressiva desvalorização das relações pessoais centradas no líder, como visto nos períodos anteriores, conduzindo o setor a se adaptar às novas condições de se relacionar com o Estado e obter benefícios.

3 Dados retirados do site da FNDC/Donos da Mídia: <www.donosdamidia.com.br>, em março de 2015. 


\section{Um modelo baseado no líder: Caldas Júnior e os vínculos de natureza pessoal}

A empresa Caldas Júnior teve como seu primeiro empreendimento jornalístico o jornal Correio do Povo ${ }^{4}$, fundado em 1895. Tal jornal despontava, no momento de seu surgimento, como o único do estado a não ter vínculos partidários e religiosos diretos, constituindo-se como uma empresa familiar. Esse fato é frequentemente apresentado como um dos fatores que contribuiu para que o jornal permanecesse por décadas com a maior tiragem e circulação do Rio Grande do Sul. A empresa, que mais tarde adquiriu a transmissão de rádio e a concessão para televisão, chegou a ser na década de 1970 a sétima maior do ramo em todo o país e o seu proprietário, Breno Caldas, possuir a sexta maior riqueza do Brasil. Em 1972, a revista Exame divulgou um levantamento em que o Correio do Povo apareceu em primeiro lugar como jornal com a maior rentabilidade entre os diários nacionais (Caldas; Machado, 1987).

Mas, apesar de a empresa ter se constituído por não apresentar vínculos partidários diretos, as relações indiretas estabelecidas com o mundo da política governamental e partidária concederam ao jornal e, mais diretamente, ao seu proprietário o reconhecimento como um dos homens mais importantes e "poderosos" do estado, a ponto de influenciar certas medidas governamentais (Barros, 1989; Braga, 2001). A análise que será abordada aqui tem como ferramenta metodológica o exame do percurso biográfico do seu diretor, manifesto em relatos jornalísticos, trabalhos acadêmicos e biografias.

Breno Caldas assumiu a direção do jornal em 1935 e permaneceu neste cargo até a venda da empresa em 1986. Portanto, foram mais de 50 anos à frente das principais articulações, negociações e definições do conteúdo jornalístico da empresa, o que lhe exigia trabalho e intenso investimento nas redes de relações, sobretudo, com a política, setor bastante interessado nas matérias jornalísticas do Correio do Povo. Essa larga experiência lhe permitiu certa habilidade e, ao mesmo tempo, um controle sobre os laços e vínculos fundamentais para a manutenção da empresa.

Suas formas de negociação e troca com o universo da política se manifestavam, na maior parte das vezes, por meio de encontros informais, como reuniões, almoços e conversas com burocratas do Estado ou até mesmo com os próprios governantes. Nesses eventos se fortaleciam ligações, estreitavam-se vínculos, ampliavam-se laços e também se podia avaliar a confiabilidade do aliado, por meio das suas tomadas de posição. Como destacam outros estudos sobre as dinâmicas das relações dos empresários com o Estado (Bezerra, 1999; 2012), as formas de interação com a esfera estatal exigem não só dedicação, mas também o domínio de um conjunto de capacidades que se adquirem pelo contato constante com pessoas vinculadas à administração pública e pela participação em reuniões e eventos cujo objetivo é promover a aproximação entre Estado e empresas.

4 O grupo Caldas Júnior contava na década de 1960 e 1970 com a rádio Guaíba AM; os jornais impressos Correio do Povo, Folha da Tarde e Folha da Manhã e o canal de televisão aberto TV2 Guaíba, com produção local de toda a programação. 
Os homens que chegavam ao poder no Estado e no País aprenderam logo a prática lição de Ernesto Dorneles e Getúlio Vargas. Para estar bem com o Rio Grande era preciso estar bem com o Correio e para estar bem com o Correio era preciso estar bem com Breno Caldas. Para estar bem com Breno Caldas era preciso reverenciá-lo nas ocasiões apropriadas e, de preferência, nunca dizer-lhe não (Galvani, 1995, p. 380).

Uma dessas ocasiões apropriadas, recorrentes nos relatos sobre a história da empresa, era a comemoração de aniversário do jornal, que se tornou um dos espaços mais importantes de encontros políticos. Nessa festa, faziam-se presentes líderes religiosos, presidentes de clubes sociais, deputados, senadores, prefeitos e até mesmo o governador do estado do Rio Grande do Sul. Essa festa caracterizava-se como um momento de firmar relações e compromissos já estabelecidos, bem como fazer novos contatos. A presença quase obrigatória de governadores e prefeitos na comemoração passou a se tornar a marca do jornal, sobretudo nos períodos de maior ascensão (Strelow, 2010). Quando algum político não podia comparecer, mandava um representante ou telegrama de congratulações. Essa prática cresceu até chegar ao apogeu econômico da empresa, nos anos 1960, em que a frase corrente no jornal era: "tomou posse no Piratini, mas foi ungido na visita ao Correio" (Galvani, 1995, p. 350). Isso queria dizer que quem não visitava o "Dr. Breno Caldas” não estava exatamente "no poder" do Rio Grande. Assim, passou a se estabelecer como norma a visita dos governadores quando empossados à empresa Caldas Júnior e, só quando havia alguma briga ou desacordo relevante, o governador, o prefeito e os comandantes militares não compareciam até o prédio da Caldas Júnior.

No relato do empresário em uma entrevista, logo após decretar falência em 1989, esses vínculos são ainda retratados:

Eu posso dizer, sem imodéstia, que eu era uma das figuras aqui no Rio Grande... Eu era consultado... Pelo menos era considerado... As pessoas que decidiam, sempre queriam saber: o que será que o Correio pensa? O que será que o Correio vai fazer? Não era uma preocupação em relação ao Breno Caldas... O Breno Caldas é igual aos outros. O Breno Caldas e o Zé da Silva dá no mesmo... O importante era o Correio do Povo. Quem chegava a Porto Alegre, vinha me visitar, apresentar cumprimentos, aquelas conversas todas... Aliás, devo dizer que eu não gostava muito disso - não sou muito chegado a esse tipo de coisa. Mas, por outro lado, isso me satisfazia muito, pois eu constatava como o Correio do Povo era considerado. Afinal, era uma obra do meu pai, que a minha mãe conseguiria manter e a que eu dei continuidade (Caldas; Machado, 1987, p. 26).

Tal relato é revelador de um conjunto de aspectos, dentre os quais se pode destacar a importância da imprensa para a política governamental, no sentido de os jornais colaborarem com o Estado por meio de seus noticiários e de como os dirigentes das empresas jornalísticas valiam-se dessa importância para consolidar um espaço destacado na política e no mercado de serviços jornalísticos, na concorrência com outros jornais. A utilização de expressões tais como "eu era uma das figuras", "eu era consultado", "eu era conside- 
rado" revela a importância que assumia a relação de estima e de apreço e como isso lhe concedia poder de influência. Ao afirmar que "não gostava muito disso", o empresário procura se isentar dessa relação que, aos poucos, estabeleceu e que lhe concedeu a formação de uma rede de contatos.

A adesão do jornal a diversos políticos, como Getúlio Vargas, e posteriormente ao golpe militar de 1964 era uma prática corriqueira. Mas o apoio oferecido pela empresa não estava separado da relação estreita que mantinha com eles. Além de receber condecorações e homenagens dos governos militares do golpe de 1964, Breno Caldas costumava oferecer churrascos em seu haras ${ }^{5}$ para receber os presidentes militares quando estes estavam no estado do Rio Grande do Sul. Esses encontros visavam aproximar a empresa dos militares, ao mesmo tempo em que tinham como objetivo deixar explícita a autonomia do jornal nas publicações e conteúdos que Breno Caldas considerasse relevantes (Caldas; Machado, 1987).

Prática comum também no jornal era despedir jornalistas que eram contra os "amigos da casa" e contratar aqueles indicados por tais "amigos". Dois casos ilustram essa situação. O primeiro deles foi o caso da demissão do redatorVianna Moog, em função de ter publicado, em 1936, uma crônica no jornal criticando, indiretamente, o embaixador Oswaldo Aranha. Oswaldo Aranha, além de ser o nome mais cotado para suceder Getúlio Vargas e amigo de Breno Caldas, havia impedido, em 1929, a venda do Correio do Povo a Assis Chateaubriand, o que concedia certa dívida pessoal do jornal com o político. O segundo foi o caso da contratação do jornalista Arlindo Pasqualini, em 1930, a pedido do seu irmão, político e senador Alberto Pasqualini. Arlindo Pasqualini tornou-se um dos principais jornalistas e articuladores do Correio do Povo (Galvani, 1995).

A rede de relações do empresário contribuía diretamente para determinar o recrutamento e a contratação dos jornalistas e, além disso, oferecia aos repórteres possibilidades de carreira. É o caso de jornalistas que, atuando em certos setores do jornal, conquistavam empregos na burocracia pública. Como exemplo disso, podemos citar o caso do jornalista Marco Antônio Kramer, que começou como repórter do setor de militares no Correio do Povo, ascendeu à direção da sucursal do Correio em Brasília e, em seguida, foi convidado para ser porta-voz da presidência e para presidir a Empresa Brasileira de Notícias (EBN), reforçando assim os laços da Caldas Júnior. Ao mesmo tempo, ele também se tornava um apoio da empresa dentro do Estado.

Essa rede mantida por laços de amizade implicava um apoio recíproco entre os envolvidos, em que a troca de favores se tornava uma peça fundamental. Estabelecidas no trabalho, e ainda reforçadas nos espaços de lazer, essas redes, que se formavam através de amizade, parentesco e aliança política, tinham importância dependendo das situações e dos fins para os quais eram mobilizadas. As obrigações e os compromissos que envolvem os vínculos constituem os princípios que estruturam as ações daqueles que participam de uma rede de relações pessoais. Nesse sentido, fazer um favor requer necessariamente uma ação

5 O Haras do Arado, como era denominado, teve grande projeção na equinocultura nacional, com a criação de cavalos puro-sangue inglês de corrida. Breno investiu pesadamente em cavalos para concorrer aos grandes prêmios nacionais. 
compensadora por parte daquele que o recebe. Do mesmo modo que a troca de serviços e favores dá início a relações pessoais, os presentes, além de serem concedidos a pessoas com as quais já se estabelecem vínculos diversos, contribuem para aproximar aquele que presenteia daquele que recebe, impondo novas relações (Bezerra, 1995). Assim, as homenagens e as condecorações, como as recebidas por Breno Caldas pelos governos militares, podem ser entendidas como formas de estabelecer uma relação de proximidade. O Estado, ao prestigiar simbolicamente certos empresários, cria as condições para a obtenção de benefícios, pois aquele que recebe o "presente" fica comprometido, vendo-se na obrigação de retribuí-lo. Neste contexto, mais especificamente, a relação entre os empresários e o Estado estava fundamentada em alianças e vínculos pessoais, na maior parte das vezes, com burocratas responsáveis por agências setoriais que poderiam servir como mediadores e facilitadores.

Desse modo, a influência de Breno Caldas estava respaldada nas relações diversas que ele estabelecia, especialmente com o universo da política governamental. Os investimentos da empresa no setor televisivo, bem como a renovação de seu equipamento técnico e modernização revelam as relações que o empresário mobilizou. A motivação ao investimento no setor televisivo ocorreu em função da concessão para a televisão que o empresário já possuía e cujo prazo já havia expirado, pois ele ainda não havia criado a emissora de televisão. $\mathrm{O}$ governo, que naquele momento estava investindo no setor e já havia liberado várias concessões, estava pressionando: ou o empresário criava a televisão ou perdia a concessão. Para não perdê-la, Breno Caldas precisou acionar seu conjunto de relações, entrou em contato com o general Geisel, candidato à sucessão do então presidente Médici, e que havia oferecido "ajuda" ao Correio do Povo, e conseguiu nova concessão. Sua relação com os presidentes militares estavam fundamentadas em laços pessoais estabelecidos por Breno. O general, que comandou o movimento da ditadura de 1964, no Rio Grande do Sul, era irmão de um grande amigo seu e, logo que o movimento ganhou expressão, tornou-se também amigo de Breno. Seu filho, quando serviu o exército, foi motorista do presidente militar Costa e Silva. Além disso, muitos oficiais eram conhecidos seus da prática de hipismo, espaço que se tornou importante meio de expandir seus contatos.

Eu estava naquela de faz não faz... Hesitava muito. E aí o presidente Médici me disse: "Vai em frente! A TV Guaíba vai dar certo!". Nesse meio tempo, enquanto pesávamos os prós e contras, a concessão da TV caducou, e eu mandei o Francisco Antônio, meu filho, que era gerente da empresa, à Brasília para falar com o General Geisel, que era candidato à sucessão de Médici e tinha se oferecido para ajudar o Correio do Povo no que precisasse. E ele deu um jeito. No ministério das Comunicações, arrumaram uma interpretação da lei para que nós pudéssemos recuperar a concessão da TV: cassaram a concessão antiga e nos deram uma outra, mediante nova concorrência (Caldas; Machado, 1987, p. 29).

Nesse momento, Roberto Marinho, empresário do ramo das comunicações em nível nacional, propôs a Breno Caldas tornar o canal de televisão filial da Rede Globo no Rio Grande do Sul e ele não aceitou, pois queria ter controle sobre o seu próprio negócio. 
Convém mencionar que Roberto Marinho despontava, nesse momento, como grande empresário no ramo das comunicações e que também contava com apoio dos militares e de verbas publicitárias estatais. Conforme relata Herz (1989), durante o processo da Comissão Parlamentar de Inquérito instaurada contra a empresa em 1966, para investigar a utilização de capital estrangeiro, as relações estabelecidas entre Roberto Marinho e os militares presidenciais, como Castelo Branco e, posteriormente, Costa e Silva, contribuíram para a emissão de muitos pareceres favoráveis à empresa e a sua legalização. Isso significa que não só em nível local, mas também em nível nacional, as relações pessoais com o Estado constituíam maneiras de estruturar esses espaços e de fazer com que funcionassem, permitindo, inclusive, a ascensão empresarial. Nesse contexto, a concorrência entre os jornais e as empresas jornalísticas acontecia em torno dos benefícios oferecidos pelo Estado.

O fato de o proprietário da Caldas Júnior ter negado a oferta de seu "amigo" o fez investir rapidamente no setor televisivo e os empréstimos aumentaram, endividando a empresa. Para se livrar da situação falimentar em que se encontrava, o proprietário do Correio do Povo recorreu a sua rede de relações e acionou o general Golbery do Couto e Silva, que havia sido seu colega no Colégio Militar, em Porto Alegre, e que, naquele momento, era chefe da Casa Civil do governo de João Figueiredo. Contou também com a participação de toda a equipe econômica liderada pelo ministro da Fazenda, Delfim Neto, para realizar o resgate da situação da Caldas Júnior. Seria feita a consolidação de todos os débitos através de um empréstimo da Caixa Econômica Federal, aprovado pelo Conselho Econômico Social.

Entretanto, o socorro não cumpriu o objetivo e foi sugerido a Breno Caldas, por Delfim Neto, que ele utilizasse a resolução $63^{6}$, que permitia o empréstimo em dólares. O empréstimo foi feito e, com a maxidesvalorização da moeda em 1979, as dívidas cresceram, o que o levou a fazer mais empréstimos no Banco do Brasil, na Caixa Federal e no Banco do Estado do Rio Grande do Sul.

Em função dessa dívida, Breno Caldas propôs ao governo a consolidação delas no Banco do Brasil. Assim, todas as dívidas seriam reunidas e unificadas no Banco do Brasil e, como garantias, bens particulares seriam oferecidos. Contudo, a consolidação dos débitos aceita pelo presidente do Banco do Brasil foi sendo adiada e, consequentemente, surgiram obstáculos à aceitação dos bens do empresário, até que ela foi negada. No início de 1980, Breno Caldas teve a primeira execução ajuizada promovida pelo Banco do Estado do Rio Grande do Sul. Nesse período, o governador era Amaral de Souza, com quem o referido proprietário do jornal não estabelecia “boas relações” e já havia se desentendido algumas vezes, portanto, não poderia recorrer ao governo estadual. Logo depois vieram as execuções do Banco do Brasil e da Caixa Federal (Galvani, 1995).

Depois de vender algumas propriedades, Breno Caldas, já sem recursos para manter o jornal, pediu emprestado ao diretor da CORAG (imprensa oficial do Estado) equi-

6 A resolução 63, do Conselho Monetário, autorizava os bancos nacionais a repassar créditos obtidos no exterior (Bezerra, 1995). 
pamentos para colocar o Correio nas ruas novamente. Mas Maurício Sirotsky Sobrinho, dono do jornal Zero Hora e da Rádio Gaúcha, os principais concorrentes da Caldas Júnior, soube da regalia e entrou em contato com o então governador do estado, Jair Soares, de quem era amigo, pedindo-lhe que lhe fosse dado o mesmo tratamento. Tal situação levou o governador a desautorizar os empréstimos das máquinas. Breno Caldas, logo após decretar falência, relatou em entrevista sua visão dos fatos:

O Jair fez uma ursada comigo. O Jair é como os outros políticos [...]. Mas naquela época quando ele pôde, ele saltou fora. Ele prometeu que ia providenciar, eu fui para o jornal e nada! Tudo ficou muito claro: ele queria deixar a coisa acontecer mesmo! Queria que o Correio não conseguisse circular... O Jair era muito ligado a um grupo de concorrentes nossos. Eles têm defunto enterrado juntos. Eu já sabia, mas aquilo foi a confirmação. Ele me ursou mesmo! (Caldas; Machado, 1987, p. 55)

Pode-se perceber, nessa declaração, a importância que as relações de amizade assumem para atingir determinados objetivos ou conseguir algumas vantagens. Ao falar "ele me ursou mesmo", "fez uma ursada comigo", o empresário contesta os procedimentos desleais e a traição, ao mesmo tempo em que menciona que a política funciona nessas condições, quando se refere a Jair "como os outros políticos". Além disso, convém observar que as incompatibilidades e as desavenças pessoais são vistas e apresentadas como explicação para o sentido que tomam certos fatos. Quando Breno Caldas afirma que Jair "era muito ligado a um grupo de concorrentes nossos e por isso queria que o Correio não conseguisse circular" (Caldas, 1987, p. 55), ele está considerando que o governador era amigo de outros e por isso deveria atender ao pedido desses amigos.

Para melhor compreender como as desavenças pessoais são apresentadas como justificativas no desenrolar dos acontecimentos, torna-se interessante mencionar as relações estabelecidas entre Breno Caldas, Amaral de Souza e Jair Soares. Amaral de Souza desentendeu-se com Breno Caldas quando era ainda vice-governador do estado, em razão de uma publicação do jornal Folha da Manhã afirmando que a festa de 15 anos da filha de Amaral havia sido paga com dinheiro dos cofres públicos. Tal matéria gerou certos mal-entendidos entre o jornal e o vice-governador. Mas esse mal-entendido foi reforçado em outras ocasiões. Durante um almoço organizado pelos militares para obter informações a respeito da aceitação dos empresários quanto à possibilidade de tornar Amaral de Souza governador do estado, o proprietário da empresa Caldas Júnior afirmou: “O Amaralzinho está abaixo do nível necessário... Falta-lhe, pelo menos, um palmo e meio. Em todos os sentidos. Físico, pessoal e moral" (Caldas; Machado, 1987, p. 42).

Além de Amaral, Jair Soares se desentendeu também com o referido empresário. Um dos desentendimentos está relacionado ao fechamento da Borregard, fábrica de celulose instalada na cidade de Porto Alegre. Nessa época, Jair Soares era secretário da Saúde e, conforme relata Galvani (1995), ficou isolado, sem qualquer respaldo público e político, depois do fechamento da fábrica, em função de uma campanha antipoluição liderada pela Caldas Júnior. A campanha iniciada pelo Correio do Povo atingiu tais proporções que, 
segundo Jair Soares, em depoimento a Galvani (1995), o governador ficou contra a parede. Por conta do mau cheiro provocado pela fábrica em dias de vento e por ter poluído parte do rio Guaíba, caso a empresa não resolvesse o problema, ela teria de fechar. Nesse momento, comentavam a Jair Soares: "Fechaste a fábrica só porque ela cheirava no nariz do Breno?" (Galvani, 1995, p. 479).

Breno Caldas, em entrevista logo após a venda da empresa, em 1984, para o agropecuarista Renato Ribeiro, ao falar de sua falência, relatou:

O fato é que todos, por motivos misteriosos, ou, pelo menos, por motivos que até hoje não estão bem claros para mim, me faltaram [...]. (Caldas; Machado, 1987, p. 34)

[...] Eu achava que estava indo tudo bem. E aí aconteceu! Veio tudo ao mesmo tempo... Surgiram as dificuldades...do ponto de vista jornalístico, financeiro, trabalhista... tudo ao mesmo tempo!E eu fiquei muito só[...] (Caldas; Machado, 1987, p. 27).

O que se percebe nessas citações e em declarações como "o fato é que todos me faltaram" ou "eu fiquei muito só" é a quebra de expectativas que se tem com relação aos amigos e a atuação destes em termos práticos e instrumentais. Os vínculos e as ligações estabelecidas com a política parecem não ter rendido os frutos que se esperava, o que se confirma também em outra declaração do empresário no momento em que pediu ajuda ao governo para sair da situação falimentar em que se encontrava:

Eu queria apenas as vantagens usuais, digamos assim, as facilidades legais e legítimas que pudessem ser concedidas a qualquer grande empresa. Eu ainda tenho as minhas dúvidas... Mas acho que Delfim estava a par de toda essa velhacaria que fizeram comigo. É uma impressão íntima. Impossível acontecer tudo o que aconteceu comigo sem o conhecimento dele. Até mesmo porque eu tive contatos freqüentes com ele, em várias oportunidades. E ele sempre dizendo que eu não me preocupasse... sempre acenando com coisas... que ia me arrumar um negócio aqui, outro ali, um negócio com o Moreira Salles... até com o Roberto Marinho ele me falou em arrumar alguma coisa...Mas a verdade é que ele nada fez para minimizar as minhas dificuldades ou viabilizar uma saída. (Caldas; Machado, 1987, p. 38).

A referência a "vantagens usuais" ou "facilidades legítimas" é reveladora da concessão de benefícios tomados como algo comum entre governo e empresas. O governo atuava como mediador dos interesses empresariais, possibilitando um "negócio aqui, outro ali" para aliviar a situação das empresas em caso de dificuldades, "viabilizando uma saída". Quando isso não acontecia, como no caso acima, o estado em que se encontrava a empresa poderia ainda atingir proporções catastróficas, levando inclusive à falência. O Estado torna-se o grande financiador e promotor de um mercado jornalístico, e a concorrência entre os jornais revela uma disputa também pelos apoios que o Estado pode oferecer. 
Mas, para ter acesso às "vantagens usuais", é necessário estabelecer uma relação com os governantes em que haja uma garantia da reciprocidade nos beneficios, ou seja, as vantagens podem ser concedidas, ao mesmo tempo em que são também recebidas.

Um comentário de um sujeito ligado ao governo me marcou muito naquela época. Ele me disse em tom confidencial: "Vou contar uma coisa ao senhor, Dr. Breno. O senhor não é considerado homem de confiança do governo. Mas como? - eu me surpreendi. Sim...é que o senhor não é confiável... até o fim!" Conversando, conversando, o sujeito foi me dizendo essas coisas. A impressão dele é que o pessoal do governo sentia que não podia contar comigo sempre, em qualquer circunstância... que eu era ótimo e enquanto estivesse aliado a eles, mas de repente, podia não estar mais, pois não tinha qualquer outra ligação que não fosse uma vinculação volitiva. Eles achavam que não podiam contar comigo porque eu não aceitaria um compromisso. "O Breno é muito nosso amigo, mas não é incondicional”- era assim que eles me viam. E tinham razão. (Caldas; Machado, 1987).

Observa-se, na citação acima, a importância que a "confiança" e a "incondicionalidade" assumem para as ligações baseadas nas redes pessoais e como isso é usado publicamente para justificar o rumo que tomam certos acontecimentos, no caso, a falência. As relações pessoais que funcionam com base na amizade têm como regra a confiança de que certos favores serão concedidos e que a reciprocidade e a aliança não serão quebradas. A troca de favores é uma das finalidades das alianças diádicas e permite, ao aliado, demonstrar interesse na união. Nesse sentido, a incerteza de que o ciclo de reciprocidade será mantido pode transformar o amigo ou o aliado em um potencial inimigo, uma pessoa que pode criar dificuldades e obstáculos (Bezerra, 1995).

Ainda é possível mencionar que os aliados de longa data podem perder a sua importância e atratividade quando aliados mais úteis entram em cena. Isso está relacionado ao fato de que as alianças são formadas porque ambos os aliados esperam ser úteis. As necessidades e os recursos utilizados por aqueles que estão envolvidos nessas relações mudam com o passar do tempo. Por esses motivos, a confiabilidade dos aliados é fundamental para aqueles que se engajam na construção de vínculos pessoais.

Uma das características principais das relações mobilizadas por Breno Caldas é que elas estavam centradas na sua capacidade de liderança. Segundo Landé (1977), as relações diádicas são sustentadas no líder e baseadas nos seus interesses particulares e não categoriais. É o líder que tem prestígio para mobilizar um conjunto de contatos, promover encontros e intensificar relações e são ainda seus atributos pessoais, como a riqueza, determinantes nesta relação. 


\section{A RBS e a extensão das redes de relações pessoais}

A Rede Brasil Sul iniciou com a Rádio Gaúcha, adquirida pelos irmãos Jaime e Maurício Sirotsky. Mais tarde, em 1970, os irmãos adquiriram o jornal Zero Hora ${ }^{7}$ e a concessão para televisão, dando início à empresa de telecomunicações ${ }^{8}$. O canal de televisão, denominado inicialmente TV Gaúcha, surgiu como transmissora da programação da Rede Globo de Telecomunicações no estado. Sua entrada no mercado de empresas de comunicação é acompanhada de um intenso investimento em entidades de representação empresarial, como a participação na fundação e na construção, na década de 1960, da Associação Gaúcha de Emissoras de Rádio e Televisão (AGERT) e da Associação Nacional de Jornais (ANJ), no final da década de 1970.

Contudo, a empresa que se destacou e cresceu na década de 1980 , período da situação falimentar em que se encontrava a Caldas Júnior, contou com importantes articuladores. Um deles foi Fernando Ernesto Corrêa que, com o tempo, passou a atuar como interlocutor junto ao poder central, além de representar e empresa em entidades como a Associação Brasileira de Emissoras de Rádio e Televisão (ABERT), AGERT e ANJ e atuando na elaboração da Constituição de 1988, como representante do segmento da comunicação.

[...] E é nessa condição que se torna um importante delegado dos meios de comunicação durante a elaboração da constituição de 1988, a par do permanente acompanhamento dos trabalhos normais do Congresso Nacional. Sua atuação junto aos detentores do poder não se cingiu a Brasília. Autoridades dos três poderes que vinham ao Sul, a convite ou não da RBS, passaram a ser recepcionados na Serra Gaúcha na residência de Corrêa, em Canela. Fazia parte da estratégia de relacionamento da empresa, que, segundo depõe Fernando Ernesto, em nenhum momento precisou recorrer a meios condenáveis como o tráfico de influência: "Nesses anos todos lembro só o caso de um assessor do ministro Hugo Napoleão que insinuou um dinheirinho para uma ajuda e lhe dei um corridão”. Fernando, nos contatos

7 Tal jornal era o nome dado ao antigo Última Hora, gaúcho que, devido às tensões políticas do golpe militar, foi fechado e vendido a uma nova empresa.

8 A Rede Brasil Sul (RSB), afiliada da Rede Globo de Televisão no estado, hoje é uma das maiores redes de comunicação da América Latina e conta com diversas filiais em todo o Rio Grande do Sul e ainda em Santa Catarina. Possui um complexo de emissoras de rádios AM e FM, bem como canal de televisão aberto e a cabo, e ainda dois jornais impressos diários produzidos na cidade de Porto Alegre. A RBS é também a empresa que mais emprega jornalistas no estado do Rio Grande do Sul. Em Santa Catarina, conta com as rádios AM Diário da Manhã, de Florianópolis, e Princesa, em Lages. Do complexo de rádios FM, conta com a Atlântida, Itapema, Rádio Metrô e rádio Cidade. Dos jornais diários, no Rio Grande do Sul, o grupo possui o Diário de Santa Maria, na cidade de Santa Maria, o Pioneiro, que atinge a região do Vale dos Sinos, Zero Hora e Diário Gaúcho, ambos em Porto Alegre. No estado de Santa Catarina: A Notícia, em Joinville, Diário Catarinense e Jornal de Santa Catarina. Ainda detém o canal a cabo TV COM e Canal Rural e o canal aberto RBS TV, com transmissão da programação da Rede Globo de Televisão e produção local. Também pertencem ao grupo uma empresa de marketing, Kzuka, um selo fonográfico, Orbeat Music, e uma editora de livros e coletâneas, a RBS Publicações. 
com o Ministério das Comunicações, sempre se valeu do relacionamento com amigos que atuavam naquele órgão, como os advogados gaúchos Mário César Degrazzia Barbosa e Poty Chabalgoity, e de pessoas do segundo e terceiro escalões do ministério, que acabavam facilitando a tramitação de processos. Assim, os processos da RBS andavam com mais rapidez do que os encaminhados pela Rede Globo diretamente ao ministro e até o presidente da República. Homem-chave da RBS em Brasília, primeiro com o apoio dos primeiros diretores, Julio César Pacheco e Edgar Laurent, depois com a contribuição de Ana Amélia Lemos, ajudou a transformar a sucursal do DF em autêntica embaixada do Rio Grande e de Santa Catarina na capital da República. Fernando Ernesto teve papel importante e decisivo nas relações institucionais da empresa na Praça dos Três Poderes. Embora ele diga que sua ação só chegava ao nível de ministros ("com presidente da República é conversa para dono de empresa...”), Fernando sabia como ninguém chegar aos seus objetivos, levando para as áreas técnicas do governo a colaboração valiosa de engenheiros como os diretores da RBS TV, Ivo Facca e Fernando Ferreira, ou usando seu charme e ramos de flores para conquistar a simpatia da filha do ministro Quandt de Oliveira, que era a todo-poderosa auxiliar do Ministério das Comunicações (Schirmer, 2002, p. 54-55).

Dessa declaração podem-se destacar dois aspectos fundamentais: o primeiro referente ao funcionamento da imprensa, o segundo referente às mudanças estabelecidas nas relações entre empresa de comunicação e governo. $\mathrm{O}$ primeiro aspecto é concernente ao quanto recorrer às relações pessoais para a obtenção de benefícios e serviços constitui uma prática recorrente, concebida como natural e legítima, contrariamente ao que ocorre com práticas como suborno, corrupção e "tráfico de influências", tidas como condenáveis. Nota-se que o bom relacionamento e a amizade com pessoas que ocupam posições destacadas podem contribuir para agilizar processos, "facilitando a tramitação". Esse tipo de relacionamento com pessoas-chave permite usufruir de um tratamento que contribui para superar os limites da formalidade. Assim, um amigo bem posicionado pode fazer com que um processo, o qual dentro das suas formalidades pode levar meses e até anos para ser analisado, seja rapidamente encaminhado. Além disso, como se tem mostrado, a doação de presentes, conforme a declaração acima, que salienta que "usando seu charme e ramos de flores para conquistar a simpatia da filha do ministro, a todo-poderosa auxiliar do Ministério das Comunicações", constitui um meio através do qual se procura estabelecer uma relação de proximidade com os ocupantes de cargos públicos, envolvendo-os em obrigações e criando condições para a obtenção de benefícios ou de um tratamento privilegiado por parte daqueles que ocupam tais posições. Além disso, o estabelecimento de tais relações exige um investimento em eventos e encontros sociais, como recepcionar pessoas que ocupam cargos importantes e destacados na política em sua residência.

O segundo aspecto que merece destaque está relacionado à necessidade, apresentada no relato, da diversificação dos contatos, não se restringindo apenas ao poder central, mas abarcando os três poderes para conquistar espaços e ampliar as relações. $\mathrm{O}$ contato com várias pessoas que atuam nesses poderes, desde o segundo e terceiro escalão até 
postos-chave, permite vantagens maiores do que o contato direto apenas com ministros ou com o presidente da República. Tal diversificação pode ser observada no contexto da redemocratização como uma das principais marcas das relações entre empresas e Estado. Nos anos 1980, há uma forte descentralização nas relações com outros setores, e o modelo baseado na presença marcante do Estado cede lugar a novas formas de acesso à política, como destaca Gros (2003). Essas novas formas incluem as associações e os grupos de empresários como estratégia para representação no processo de elaboração da nova Constituição.

Cabe ressaltar que, diferentemente do caso da empresa Caldas Júnior, onde as relações centravam-se na pessoa do proprietário Breno Caldas e davam-se diretamente entre ele e o poder governamental, no caso da RBS, a empresa valeu-se da atuação de intermediários. Os intermediários não desempenham funções públicas nem ocupam cargos públicos; sua atuação é preferencialmente fora do Estado. Mas, por circularem nesse meio, eles acumulam certo poder e uma relação especial com a máquina pública. Sua influência e seu poder resultam do conhecimento que adquirem do funcionamento da esfera governamental e das relações informais mantidas com as pessoas responsáveis pela operacionalidade do sistema, conforme visto na citação acima. Por essa via, eles conseguem fazer com que as necessidades da empresa recebam um tratamento particular, contribuindo, muitas vezes, para transformar os interesses da empresa em interesses e ações do Estado. Sua função é transformar interesses privados em acordos institucionais. Os intermediários são "peças-chave" que ajudam a resolver os problemas e as dificuldades da empresa junto ao Estado, acumulando ao mesmo tempo conhecimentos técnicos e pessoais. Como apontou Bezerra (1995) em um estudo sobre a relação entre as empresas e o Estado, apesar de não estar centrada na relação direta com a pessoa do proprietário, a lógica que constrói a relação estabelecida pelos intermediários é a mesma, ou seja, baseada nas mesmas condições da lógica pessoal. Tal lógica envolve as mesmas práticas, como as trocas de favores, bens e serviços, bem como uma série de compromissos, reciprocidades, lealdades e retribuições, que são próprias das relações interpessoais. Além disso, o intermediário (broker) constitui sua trajetória e reforça seu papel na rede pela força do seu capital de relações (Boissevain, 1987)

Entretanto, as ligações da empresa com a política não se limitaram ao estabelecimento desses intermediários. Em 1986, com a vitória do PMDB, o nome de Maurício Sirotsky Sobrinho passou a ser cogitado para se tornar candidato de consenso ao governo do Rio Grande do Sul.

Lideranças de vários partidos, desde o governador Jair Soares ao PMDB, asseguraram apoio à iniciativa que acabou tendo o aval do presidente José Sarney. E a formalização do convite do presidente a Maurício foi atribuída ao ministro da Educação Jorge Bornhausem (Schirmer, 2002). 
O convite não chegou a ser formalizado, porque Maurício Sirotsky faleceu antes que isso acontecesse. Na citação abaixo, podemos observar mais elementos da relação entre a empresa e a política governamental.

Fernando Ernesto Corrêa, no entanto, um dia em Brasília viveu um episódio insólito e constrangedor, no gabinete do então ministro das Comunicações Antônio Carlos Magalhães (ACM), em reunião na qual se discutiam questões daquela área no projeto da nova constituição. Fernando Ernesto, como vice-presidente da ABERT e falando no tom que lhe é característico, quase gritando, foi interrompido por ACM:"O senhor se retire daqui. Eu não admitiria nem que o Dr. Roberto Marinho viesse me falar nesse tom”. Só restou a Fernando Ernesto retirar-se e depois, através do secretário geral do ministério, Rômulo Villar, explicar a ACM que seu jeito de falar era aquele... $\mathrm{O}$ episódio acabou entrando para o folclore político de Brasília. Fernando Ernesto passou a baixar o tom nos encontros com ACM e se tornou grande amigo do seu filho, deputado Luís Eduardo Magalhães. (A amizade com Luís Eduardo Magalhães quase levou Fernando Ernesto Corrêa a entrar na política. Quando a candidatura de Luís Eduardo à sucessão de Fernando Henrique Cardoso começou a se desenhar, Fernando Ernesto assinou ficha no PFL disposto a apoiá-lo. Mas sua tentativa de incursão na política ficou frustrada com a morte prematura do deputado baiano) (Schirmer, 2002, p. 56).

Como salientado anteriormente, as relações de natureza pessoal podem ocorrer através de distintas ligações: de parentesco, de patronagem, de amizade, de apadrinhamento, de alianças políticas, de camaradagem, de conhecimento. $\mathrm{O}$ vínculo estabelecido entre pessoas da mesma família, ou nos locais de trabalho, na amizade e nas alianças políticas adquire importância quando associadas às circunstâncias em que são acionadas (Bezerra, 1995). Até o momento, foi apontada uma série de ligações de natureza pessoal, cujo elo principal em jogo era a amizade instrumental. No entanto, no caso acima declarado, há indícios de uma ligação pessoal cuja base não é a amizade nem as alianças políticas, mas a patronagem. Como evidenciam as propostas que visam analisar esse tipo de relação, a patronagem envolve pessoas que ocupam posições díspares e assimétricas no espaço social.A desigualdade de poder que existe entre essas pessoas pode ter como base distinções econômicas, status, prestígio ou ainda acesso a recursos. Da mesma forma como nas relações de amizade, a patronagem envolve uma série de troca de favores, bens e serviços, porém entre pessoas que ocupam posições desiguais.

Nesse sentido, quando Antônio Carlos Magalhães afirma que "não admitiria nem que o Dr. Roberto Marinho viesse lhe falar nesse tom”, ele está instaurando a sua capacidade de controlar a situação e de impor quem tem mais "poder" naquele contexto, como também está definindo, dentre outras coisas, quem pode alterar o tom de voz. Fernando Ernesto Correa, quando se submete à ordem, retirando-se da sala e explicando posteriormente o motivo de sua atitude "alterada", aceita a condição de que eles estão em posições desiguais. Ao mesmo tempo, outros vínculos pessoais são estabelecidos, como o caso da amizade com Luís 
Eduardo Magalhães.Vínculos com a mesma natureza pessoal, mas que se baseiam em ligações distintas: amizade, patronagem e ainda alianças políticas através de inserção em partidos.

Além desses vínculos, a RBS inseriu-se em diversos espaços, atuando em entidades e associações civis regionais, nacionais e também de cunho internacional. Para isso contou com a presença ativa dos seus fundadores e articuladores, como Fernando Ernesto Correa, que foi presidente da AGERT por dois mandatos, de 1978 até 1982, e da ANJ. Jayme Sirotsky também foi presidente da Associação Nacional de Jornais em dois mandatos (1987/1988 e 1992/1994); presidente da Associação Mundial de Jornais e integrou o comitê executivo e a vice-presidência da Federação Internacional de Editores de Jornais. Em 1980, ele participou, como fundador, do Conselho Nacional de Auto-Regulamentação, órgão criado por iniciativa de várias entidades reunindo propaganda, meios de comunicação e anunciantes com o objetivo de estabelecer normas. Atuou ainda como vice-presidente do Conselho Nacional de Comunicação em 2002.

Como se pode ver, a RBS teve presença destacada na criação e na consolidação das principais entidades de representação empresarial do setor da comunicação, defendendo desde o treinamento e a regularização profissional do setor até a abertura ao capital estrangeiro. As associações civis desempenham um papel central, no período pós década de 1970, nas relações com o Estado. Elas permitem independência com relação aos governos e, ao mesmo tempo, servem como espaço de negociação direta com as agências regulatórias da política econômica (Diniz; Boschi, 1979).

Os investimentos da empresa pretendiam atingir proporções maiores na área das telecomunicações. Em 1996, a RBS associa-se e, depois, assume o controle da Companhia Rio Grandense de Telecomunicações (CRT), em parceria com a Telefônica da Espanha. Mas o ingresso da empresa nesse setor provocou denúncias quanto à aquisição da companhia. Essas denúncias estavam relacionadas ao fato de que o governador que iniciou o processo de privatização da CRT em 1994, permitindo a venda de 35\% do capital com direito a voto da companhia, Antônio Britto, havia sido ex-repórter da Zero Hora e ex-diretor de jornalismo da RBS TV. Além disso, as denúncias afirmavam a ampla vantagem do candidato Antônio Brito na cobertura eleitoral de 1994, realizada pelos veículos de comunicação da empresa.

Outras ligações da empresa com a política governamental seriam ainda fontes de denúncias por parte de grupos como o Fórum Nacional pela Democratização da Comunicação e o Sindicato dos Jornalistas Profissionais do Rio Grande do Sul. Em final de 2002, a RBS anunciou como vice-presidente executivo Pedro Parente, ministro-chefe da Casa Civil do governo Fernando Henrique Cardoso, que, depois de deixar o cargo, assumiria a vice-presidência da empresa em fevereiro de 2003. As denúncias apontavam o favorecimento de Pedro Parente a empresas de comunicação, assinalando que o ministro estava envolvido na Medida Provisória $n^{\circ} 70$, editada em $1^{\circ}$ de outubro de 2002, que alterou as regras de controle das empresas de radiodifusão, permitindo novas concessões e capital estrangeiro na mídia. As acusações salientavam que Pedro Parente havia sido libe- 
rado da quarentena (período de quatro meses) exigida para servidores que ocupam cargos no primeiro escalão e que migram para a iniciativa privada. ${ }^{9}$

A relação que os dirigentes das empresas de comunicação mantêm com o governo também pode ser percebida pela constante migração de pessoas que ocupam posições em órgãos estatais a empresas privadas ou vice-versa. Essas pessoas, ao exercerem funções em instituições públicas, acumulam informações sobre a dinâmica da burocracia governamental e, ao mesmo tempo, estabelecem uma série de relações com a política governamental, que podem inclusive ser acionadas para atender os negócios das empresas às quais estão vinculados (Bezerra, 1995).

Além desses investimentos, a RBS, assim como outras do ramo das comunicações no Brasil, concentra seus esforços em atividades sociais envolvidas na "responsabilidade social" da empresa. Essa "responsabilidade social" traduz-se em projetos de ajuda a comunidades e grupos carentes em que a empresa se atribui um papel essencial na "construção da cidadania brasileira” e na definição de problemas que merecem cuidados do Estado. Tais projetos de "responsabilidade social" legitimam o papel das empresas como atores sociais diretamente envolvidos na política estatal. Iniciados em 1982, com a criação da Fundação Maurício Sirotsky Sobrinho, esses projetos ganham fôlego a partir de 1995, quando a empresa redireciona seus investimentos e muda de ação filantrópica e de assistência social "para agência de fomento ao desenvolvimento econômico e social". Nesse novo momento, a fundação buscou parceria com uma assessoria alemã, que prestava serviços técnicos ao Estado (Schirmer, 2002). A fundação, além de seus projetos que concorrem anualmente a prêmios como os de Responsabilidade Social, criados por órgãos estatais como Assembleia Legislativa do Rio Grande do Sul, presta assessoria para empresas que desejam realizar projetos sociais. Por meio desses projetos, as empresas, como já salientado por outros trabalhos sobre o universo empresarial (Gros, 2003; Diniz, 2010), ampliam suas intervenções na política e consolidam sua participação nas propostas e nas políticas de desenvolvimento do país.

Esses dados permitem revelar que a empresa RBS precisou mobilizar um conjunto diversificado de vínculos sociais para ter acesso a determinados recursos, materiais ou simbólicos. Esses vínculos compreendem alianças políticas, como inserção em partidos, laços de amizades e ainda ligação de patronagem, compondo assim uma rede de relações distintas. $\mathrm{O}$ conjunto dessas relações pessoais estabelecidas constitui uma rede social que é comumente definida como "matrizes de vinculações sociais" ou ainda "campos sociais constituídos de relações entre as pessoas" (Landé, 1977). Essas redes incluem todas as pessoas que se encontram em um determinado espaço social e que estão próximas, direta ou indiretamente, umas das outras, ocupando posições iguais ou desiguais. O êxito das estratégias da RBS está relacionado à diversificação das atividades e à ampliação das redes, incluindo não só redes pessoais, de amizade, políticas, mas também o forte investimento em redes institucionais.

9 Dados divulgados na revista Cadernos de Porém, n. 1, novembro de 2003, Porto Alegre. 


\section{Considerações finais}

Este artigo procurou demonstrar a dinâmica da relação do empresariado do setor da comunicação com a política, com intuito de identificar certas modalidades. Portanto, nosso interesse central consistiu não nas condições do sucesso empresarial ou nas formas de recrutamento dos agentes econômicos, mas nos seus padrões de ação política e como tais padrões variam de acordo com as condições históricas. A contribuição principal deste artigo incide em demonstrar, a partir de tal análise, que as empresas não são apenas agentes econômicos, mas também agentes políticos na medida em que se relacionam com as instituições governamentais e estatais. Um dos padrões que podemos identificar envolve os laços sociais, os quais se apresentam como modalidades específicas de acesso ao Estado e possíveis de serem acionadas em determinadas situações.

Além disso, o jornal, como empreendimento e como grande empresa, desenvolveu-se associado às dependências estabelecidas com a política governamental. Assim, é possível perceber que as condições sociais que tornaram possível o desenvolvimento de uma "grande imprensa" no Brasil estão relacionadas à construção e à mobilização de uma rede de relações que contribuíram para a formação, a estruturação e o funcionamento de um espaço específico de atuação jornalística. As relações de natureza pessoal, ao mesmo tempo em que se constituíram como constrangimentos organizacionais que configuraram tais espaços, compuseram os condicionantes práticos e recursos sociais mais mobilizados no funcionamento dessas instituições em certos contextos sociais. As relações entre Estado e empresariado, no caso específico aqui dos meios de comunicação, foram estabelecidas por meio da lógica pessoal, e não da lógica de mercado, constituindo-se como princípio social que fundamentou as condutas dos empresários da comunicação.

Os casos aqui explorados permitem compreender as mudanças nessas relações a partir do contexto político. De um lado, o caso Caldas Junior, com base nas relações fundamentadas nos vínculos pessoais estabelecidos pelo proprietário Breno Caldas. Tais laços lhe permitiam concentrar e controlar os contatos, mas não lhe permitiu o investimento em diversas frentes e a presença em espaços diversificados de acesso à política. Esse foi um dos fatores que o levou a se ver sozinho em um momento de dificuldade financeira. De outro lado, temos o caso RBS, com outro contexto de desenvolvimento e relações múltiplas e diversificadas, o que possibilita à empresa assegurar sua presença em diferentes espaços de representação.

\section{Referências}

ALONSO, A. Idéias em movimento. A geração 1870 na crise do Brasil-Império. São Paulo: Paz e Terra, 2002.

AUYERO, J. Clientelismo político en Argentina: doble vida y negación colectiva. Perfiles Latinoamericanos, México, n. 20, p. 33-52, jun. 2002.

Vida e política das pessoas pobres- as coisas que um etnógrafo político sabe (e não sabe) após 15 anos de trabalho de campo. Sociologias, Porto Alegre, ano 13, n. 28, p. 126-164, set./dez. 2011. 
BARNES, J. Redes sociais e processo político. In: FELDMAN-BIANCO, B. A antropologia das sociedades complexas. São Paulo: Global, 1987. p. 159-195.

BARROS, Higino. O Centauro das Rotativas. Revista Imprensa, São Paulo, ano 3, n. 25. 1989.

BEZERRA, M. O. Corrupção: Um estudo sobre poder público e relações pessoais no Brasil. Rio de Janeiro: Relume Dumará, 1995.

2017.

Corrupção e produção do Estado. Revista Pós em Ciências Sociais, Repocs, v. 14, n. 27, p. 99-130, jan/jun.

Em nome das "bases": política, favor e dependência pessoal. Rio de Janeiro: NUAP/Relume-Dumará, 1999.

Estado, representação política e corrupção: um olhar antropológico sobre a formação de fronteiras sociais. Crítica e Sociedade, v. 2, n. 2, p. 64-80, 2012.

BIANCHI, Álvaro. Empresários e ação coletiva: notas para um enfoque relacional do associativismo. Revista de Sociologia e Política, Curitiba, v. 28, p. 117-129, 2007.

BRAGA, Kenny. O mais poderoso jornalista gaúcho. Revista Press. Nomes que fizeram a história da Imprensa Gaúcha. Porto Alegre, 2001.

BRESSER-PEREIRA, L. C.; DINIZ, E. Empresariado industrial, democracia e poder político. Novos Estudos, n. 84, p. 82-99, 2009.

BRIQUET, J. L.; SAWICKI, F. Le clientelisme politique dans les societés contemporaines. Paris: Presses Universitaires de France, 1998.

BOISSEVAIN. J. Apresentando "Amigos de amigos!: redes sociais, manipuladores e coalizões". In: FELDMANBIANCO, B. A Antropologia das sociedades complexas. São Paulo: Global, 1987. p. 195-226.

CALDAS, B.; MACHADO, J. A. P. Breno Caldas. Meio século de Correio do Povo. Glória e agonia de um grande jornal. Depoimento a José Antônio Pinheiro Machado. Porto Alegre: L\&PM Editores, 1987.

COMBES, Hélène. ¿Dónde estamos com el estudio del clientelismo? Desacatos, México, n. 36, p. 13-32.

maio/ago. 2011.

COSTA, P. S. N. Elite empresarial e elite econômica: o estudo dos empresários. Rev. Sociol. Polit., v. 22, n. 52, p. 47-57, 2014.

; ROKS,T.J.; SANTOS FILHO, G. O. Recrutamento, valores e padrões de ação política da elite empresarial. Rev. Sociol. Polit., Curitiba, v. 20, n. 43, p. 221-246, 2012.

DINIZ, E. Empresariado industrial, representação de interesse e ação política: trajetórias históricas e novas configurações. Política e Sociedade, v. 9, n. 17, 2010, p. 101-139.

; BOSCHI, R. Autonomia e dependência na representação de interesses industriais. Dados, Rio de Janeiro, n. 22, 1979

GALVANI, W. Um século de poder. Os bastidores da Caldas Júnior. 2. ed. Porto Alegre: Mercado Aberto, 1995.

GROZ, D. Organizações empresariais e ação política no Brasil a partir dos anos 1980. Civitas, v. 3, n. 2, jul./dez., 2003, p. 273-300.

HAGGARD, S; MAXFIELD, S.; SCHNEIDER, B R. Theories of business and business-State relations, and economic transformation. In: MAXFIELD, S.; SCHNEIDER, B. R. (Ed.). Business and the State in developing countries. Ithaca: Cornell University, 1997. p. 3-35.

HERZ, D. A história secreta da Rede Globo. Porto Alegre: Ortiz, 1989.

KITSCHELT, H.Y WILKISON (Ed.). Patrons, clients and policies. Cambridge: Cambridge University Press, 2007.

KUSCHINIR, K., Antropologia e política. Revista Brasileira de Ciências Sociais, v. 22, n. 64, 2007, p. 163-167. 
LANDÉ, C. H. Introduction: the dyadic basis of clientelism. In. SCHIMDT, S. W. et al. (Ed.). Friends, followers, and factions; a reader in political clientelism. Berkeley: University of California Press, 1977, p. 13-38..

MANCUSO, W. O Empresariado como ator político no Brasil: balanço da literatura e agenda de pesquisa. Rev. Sociol. Polit., Curitiba, v. 28, p. 131-146, 2007.

MICELI, S. Intelectuais à brasileira. São Paulo: Companhia das Letras, 2001.

OFFERLÉ, M. Sociologie des organisations patronales. Paris: La Découverte, 2009.

PETRARCA, F. R. Esfera política e processos de consolidação dos saberes profissionais. In: SEIDL, E.; GRILL, I. As ciências sociais e os espaços da política no Brasil. Rio de Janeiro: FGV, 2013. p. 103-140.

Construção do Estado, esfera política e profissionalização do jornalismo no Brasil. Revista de Sociologia e Política, v. 18, p. 81-94, 2010.

SCHIRMER, L. RBS: Da voz-do-poste à multimídia. Porto Alegre: L\& PM, 2002.

STRELOW, A. A. G.. Breno Caldas: Poder e declínio de um dos mais influentes jornalistas gaúchos. BOCC. Biblioteca On-line de Ciências da Comunicação, 2010, p. 1-12. Disponível em:< http://www.bocc.ubi.pt/pag/ bocc-imprensa-strelow.pdf>. Acesso em: 20 mar. 2016.

VIDAL E SOUZA, C. Repórteres, reportagem e construção da nação no jornalismo brasileiro. 2003, 287 f.Tese (Doutorado em Antropologia Social) - Programa de Pós-Graduação em Antropologia Social, Museu Nacional, UFRJ, Rio de Janeiro, 2003. 


\title{
Personal relations networks and business practice: a study on communication companies and politics in Rio Grande do Sul
}

\begin{abstract}
This paper analyzes the role of networks of relationships between communication entrepreneurs and politics in Rio Grande do Sul. From the case study of two state communication companies, we identified a set of social and political changes that led to a diversification in the forms of relationship between business and politics. On the one hand, the period of Caldas Júnior's ascension represents a moment in which the basis of the relations between the entrepreneurship took place through the direct links with the State. On the other hand, the moment of ascension of the company Rede Brasil Sul (RBS) occurs in a context in which the relations with the political sphere had diversified and with that it was necessary to widen the networks of relations. Based on this, it was possible to identify the changes in the mechanisms of access to the politics and networks of relationships that underlie the practices of entrepreneurs.
\end{abstract}

Keywords: business, politics, personal relations, patronage, Caldas Junior, RBS.

\section{Redes de relaciones personales y práctica empresarial: un estudio sobre las empresas de comunicación y la política en Rio Grande do Sul}

\section{Resumen}

Este artículo analiza el papel de las redes de relaciones entre empresarios de la comunicación y la política en Rio Grande do Sul. A partir del estudio de caso de dos empresas de comunicación de esa ciudad, identificamos un conjunto de cambios sociales y políticos que condujeron a una diversificación en las formas de relación entre el empresariado y la política. Por un lado, el período de ascenso de la empresa Caldas Júnior representa un momento en que la base de las relaciones entre el empresariado ocurría por medio de los vínculos directos con el Gobierno. Por otro, el momento de ascenso de la empresa Red Brasil Sur (RBS) ocurre en un contexto en el que las relaciones con la esfera política se habían diversificado y, con ello era necesario ampliar las redes de relaciones. En base a ello, fue posible identificar las transformaciones en los mecanismos de acceso a la política y las redes de relaciones que fundamentan las prácticas de los empresarios.

Palabras clave: empresarios, política, relaciones personales, clientelismo, Caldas Junior, RBS. 
